\title{
EL TRÁFICO Y LA TRATA DE MUJERES RUMANAS EN LA COMUNIDAD DE MADRID
}

\author{
Silvia Marcu \\ Instituto de Economía, Geografía y Demografía \\ Consejo Superior de Investigaciones Científicas
}

\section{RESUMEN}

Tras la caída de los regímenes comunistas y el desplome soviético en el Este de Europa, ocurrieron transformaciones trascendentales. Con el telón de fondo de las transiciones económicas, políticas y sociales, aumentó de la emigración procedente de estos países, hacia los países desarrollados de la UE. Entre los múltiples tipos de emigraciones que se realizaron a partir de los años noventa, apareció en el escenario, la cara más oscura de la inmigración irregular: el tráfico de mujeres. El artículo analiza desde una perspectiva social el fenómeno del tráfico de mujeres procedentes en Rumanía, con destino España, Comunidad de Madrid. Se analiza el contexto, la situación en el origen, la organización del tráfico y la dramática situación de las víctimas en el destino. La autora considera que a pesar de las dificultades a la hora de medir y cuantificar el tráfico de mujeres, es importante realizar la aproximación a la víctima para conocer la realidad sobre esta cara negra y oculta de la inmigración internacional.

Palabras clave: tráfico y trata de mujeres, Rumanía, Comunidad de Madrid, España, inmigración ilegal.

\section{ABSTRACT}

After the fall of the communist regimes and the Soviet collapse in the East of Europe, transcendental transformations happened. With the basic curtain of the economic transitions, political and social, the fury of the emigration coming from these countries untied, towards the developed countries of the EU. Between the multiple types of emigrations that were realised from the Nineties, within the industry of the migration, appeared in the scene, the darkest face of immigration to irregular: the traffic of women. The article analyzes from a social perspective the phenomenon of the traffic of originating women in Rumania, with Spain destiny, Community of Madrid. We analyze the situation in the origin, the organization of the traffic and the dramatic situation of the victims in the destiny. The author considers that in spite of the difficulties at the time of measuring and quantifying the traffic of women, it is important to realise the approach to the victim to know the reality on this black face and hides of international immigration. 
Key words: trafficking woman, Romania, Comunity of Madrid, Spain, illegal migration.

\section{Introducción}

El análisis del tráfico ${ }^{1}$ y de trata ${ }^{2}$ de mujeres en el mercado global de la prostitución debe realizarse atendiendo al contexto social, económico y cultural que le ha dado origen y que lo sigue alimentando. Requiere un esclarecimiento de los actores que lo protagonizan, de las estructuras económicas y los sistemas sociales que lo sostienen.

El artículo analiza los mecanismos del tráfico de mujeres procedentes de Rumanía, con destino España, Comunidad de Madrid (CAM). Además de las causas que facilitan el fenómeno, su dinámica describe y analiza las etapas que constituyen el proceso en sí.

Debido a que en Rumanía, a partir de 1990 se constituyeron redes que se mostraron provechosas y que transportaron en el mercado occidental mujeres que supieron desde el principio que se dedicarían a la prostitución, el tráfico y la trata pueden confundirse con la prostitución. Pero a diferencia de las mujeres que trabajan en ese oficio, las víctimas del tráfico y de trata son transformadas en mercancías sin su conocimiento ni consentimiento, sometidas a prácticas degradantes y obligadas a prostituirse por cantidades módicas de dinero o incluso sin remuneración alguna. Además, la inexistencia de la legislación específica convierte en difícil la distinción jurídica de los fenómenos.

Consideramos que el tráfico y la trata de mujeres representan un fracaso del proceso migratorio percibido por autores rumanos (Sandu, 2006; Lazaroiu, 2000) como innovación social, y desencadenado en Rumanía después de la caída del régimen dictatorial en plena crisis de la transición del país hacia la democracia y la economía del mercado. El tráfico y la trata, como formas violentas de la inmigración irregular constituyen, pues, productos secundarios, fracasados, de la migración circulatoria Este-Oeste, determinados tanto por las características de la economía del país, como por el contexto del ámbito en el cual vive el individuo.

Las redes informales del tráfico vinieron a suplir el vacío institucional y sus efectos negativos no tardaron en aparecer: mercados negros, trata de mujeres, prostitución en los Balcanes. Mientras que el acceso a la información siga siendo deficitario y la migración circulatoria no se reglamentase al nivel europeo, las personas continúan recurriendo a trayectos de migración ocultos, plagados de riesgos.

El trayecto metodológico seguido para la realización de este trabajo fue la técnica combinada: En la primera fase, exploratoria ${ }^{3}$ se indagó en los elementos básicos para la comprensión del fenómeno del tráfico y de trata. La fase cualitativa profundiza en los mecanismos de funcionamiento del fenómeno, con la ayuda de las entrevistas en profundidad a mujeres rumanas, víctimas del tráfico y de trata de personas en la Co-

1 El tráfico incluye la captación, el transporte, el traslado, la acogida o la recepción de personas. Para llevar a cabo el tráfico se recurre a la amenaza o al uso de la fuerza u otras formas de coacción, el rapto, fraude, engaño, abuso de poder o situación de vulnerabilidad.

2 La trata de mujeres consiste en vender, controlar y restringir la libertad de las víctimas. Los transportistas y los tratantes pueden trabajar conjuntamente, en cadena: unos pueden reclutar, transportar y vender y otros pueden comprar y explotar.

3 La exploración se llevó a cabo en Rumanía y en los barrios de Madrid y de la Comunidad donde se ejerce la prostitución. 
munidad de Madrid ${ }^{4}$. La fase cualitativa ayudó a detectar, por una parte el riesgo, la vulnerabilidad de las víctimas y, por otra parte, comprobó la hipótesis interpretativa de la primera fase.

El contacto con las entrevistadas se realizó mediante la Oficina de Policía, Brigada de Extranjería del Ministerio del Interior de la Comunidad de Madrid $^{5}$. Las víctimas ayudaron a través de su testimonio a componer el trabajo, relatando el viaje del terror que sufrieron desde el origen hasta el destino. Consideramos que la originalidad del artículo consiste en la aproximación hacia la víctima, convirtiéndose las voces de las mujeres, en protagonistas.

\section{Estado de la cuestión y dificultades en la medición del tráfico}

El intenso fenómeno de la migración desde los países del Este de Europa comenzó a desarrollarse a partir de los años 1990, debido a la inestabilidad y a la incertidumbre que caracterizó la primera fase del proceso de transición hacia la democracia y la economía de mercado. La crisis hizo que miles de personas del Este de Europa emigraran para trabajar en los países occidentales (Layard, R, Blanchard, O, Dornusch, R, Krugman, P, 1992). Junto a la intensa inmigración laboral, apareció un fenómeno que se desarrolló en paralelo, y que representa la cara oculta del proceso: la inmigración ilegal, en su más oscura vertiente: el tráfico de mujeres.

Si bien su desarrollo comenzó en todos los países de la Europa del Este, pronto destacó un país, Rumanía, que por sus características geopolíticas, geográficas y sociales, se transformó en país de origen y de tránsito del tráfico de personas, especialmente de mujeres.

A pesar de las ampliaciones de la Unión Europea (UE) y de la intensidad del control fronterizo en la región, el fenómeno cobró intensidad en el área y con él, como es natural, proliferaron también los especialistas que dedicaron parte de sus investigaciones al estudio de la migración ilegal y al tráfico de seres humanos. Autores como Skrobanek, Boonpakdi, y Janthakeero (1999) Salt y Stein (1997), Uehling (2004), Nieuwenhuys y Pecóud (2007) que resaltan el papel de la Organización Internacional de las Migraciones (OIM), Kyle y Koslowski, Jandl (2007) entre los más destacados, analizaron el fenómeno del tráfico humano con especial incidencia al tráfico de mujeres. Narli (2006), Kelly (2005), Smartt (2003), Hughes (2000), Pyshchulina (2003), Leman y Janssens (2007) centraron sus investigaciones al análisis de este fenómeno, con especial incidencia a la Europa Central y Oriental.

Los estudios rumanos escasean, a pesar de la intensidad del fenómeno. Lazaroiu (2000) y Petrescu (2005) analizaron el fenómeno en sendos trabajos en las Revistas Sociologie Româneasca y Calitatea Vietii, respectivamente. Sus análisis tuvieron poco impacto internacional y la situación real del tráfico de mujeres en Rumanía se vislumbra básicamente a través de los Informes de los Organismos Internacionales. En España, más allá del

4 Las entrevistas se realizaron entre 15 de mayo y 1 de julio de 2008 en la Oficina de Policía, Brigada Extranjeros de la Comunidad de Madrid, C/General Pardiñas, 90. La autora realizó las entrevistas en el idioma rumano y las tradujo, posteriormente.

5 Las entrevistadas son víctimas del tráfico con edades comprendidas entre 15 y 35 años. La mayoría de ellas habían acudido a la Policía para denunciar el tráfico y los malos tratos, mientras que algunas habían sido arrestadas como consecuencia de las redadas organizadas por la Guardia Civil que persigue la desarticulación de bandas de traficantes de seres humanos en España, en la Comunidad de Madrid. Se observa que el discurso de las entrevistadas está relatado en pasado.

Más que un cuestionario, el guión utilizado se redujo a una conversación que ayudara a las jóvenes víctimas del tráfico de seres humanos a contar sus desgarradoras historias vitales. El hecho de que las entrevistas se realizaran en la Oficina para extranjeros, ayudó a que las mujeres pudieran vencer el miedo de la calle, sentirse más seguras al contar sus testimonios. 
mantenimiento de posturas de principio sobre el fenómeno, existen pocas investigaciones empíricas sobre las víctimas del tráfico de mujeres, tratándose más el fenómeno de la prostitución de las inmigrantes (Barajona, 2001) procedentes de América Latina (Bornelli y Jiménez, ed. 2001).

Un problema importante que explica la escasez de datos cuantitativos y de análisis, lo constituye la identificación de las víctimas. Los estudios recientes (OIM, 2006, 2007) demuestran que alrededor de un $70 \%$ de las víctimas del tráfico humano no pueden identificarse y no benefician de asistencia cualificada. Los motivos se vinculan al hecho de que las víctimas desconocen, habitualmente, la lengua del país de destino y no pueden comunicarse. Para tener acceso a las víctimas, se necesita conocer sus idiomas de procedencia. Por otra parte, las mujeres son secuestradas o mantenidas bajo estricta observación sin posibilidad de entrar en contacto con las autoridades. La única vía de acceso se produce cuando denuncian el trato, o cuando la Policía del país de destino desmantela alguna banda de traficantes.

Según la Organización Internacional del Trabajo, (OIT), el número de las personas traficadas cada año, se eleva a cerca de 2,5 millones, siendo en su mayoría, mujeres. Cerca de 500.000 proceden de Europa. Y aunque las ganancias obtenidas del tráfico son de miles de millones, la UE concede cerca de diez millones de euros anuales, para luchar contra el fenómeno. ${ }^{6}$

Según United Nations Office on Drugs and Crime, los traficantes ganan cada año 8 mil millones dólares, comparable con las ganancias obtenidas del tráfico de drogas ${ }^{7}$. EUROPOL muestra que los traficantes obtienen unas ganancias situadas entre 6 y 9 mil millones dólares. ${ }^{8}$

No existen estadística sobre el fenómeno de tráfico de mujeres rumanas pero la frecuencia con la que aparecen en la prensa internacional, sobre todo en la italiana, española y francesa, pone de manifiesto el hecho de que el número de las víctimas del tráfico es cada vez mayor.

\section{El fenómeno de tráfico de mujeres procedentes de la Europa del Este. Rutas de tráfico}

El restablecimiento de la libertad de movimiento transfronterizo tras la caída del régimen totalitario condujo a la aparición del mercado de tráfico de seres humanos en la Europa Central y Oriental. De esta manera, además de las zonas tradicionales de origen (el norte y el centro de África, América Latina, Asia), los países del centro y del Este de Europa llaman la atención, con cifras de mujeres traficadas hacia el Occidente estimadas a cerca de 120.000 cada año (OIM, 2003, 2006, 2007). Los más importantes factores generadores del fenómeno de tráfico de seres humanos se situaron alrededor de la crisis política, económica y social de la transición de los países del antiguo bloque comunista. El estallido de los conflictos étnicos en el espacio de la antigua Yugoslavia contribuyó al incremento del negocio, sobre todo con el envío de las misiones de paz, de las tropas occidentales en la región de los Balcanes. Por ello, el número de las víctimas asistidas (gráfico 1) fue mayor en esa región, y aumentó en el tiempo.

6 Informe OIT sobre el tráfico de mujeres, 2007

7 Anual Report 2008: http://www.unodc.org/documents/about-unodc/AR08_WEB.pdf

8 Anual Report 2007: http://www.europol.europa.eu/publications/Annual_Reports/ Annual\%20Report\%202007.pdf 
Albania, Moldavia, Ucrania y Rumanía y Bulgaria son tanto países de origen, como de tránsito para las mujeres traficadas con el fin de la explotación sexual en países de la Europa Occidental, como Italia, España o Grecia. (Gráfico 2)

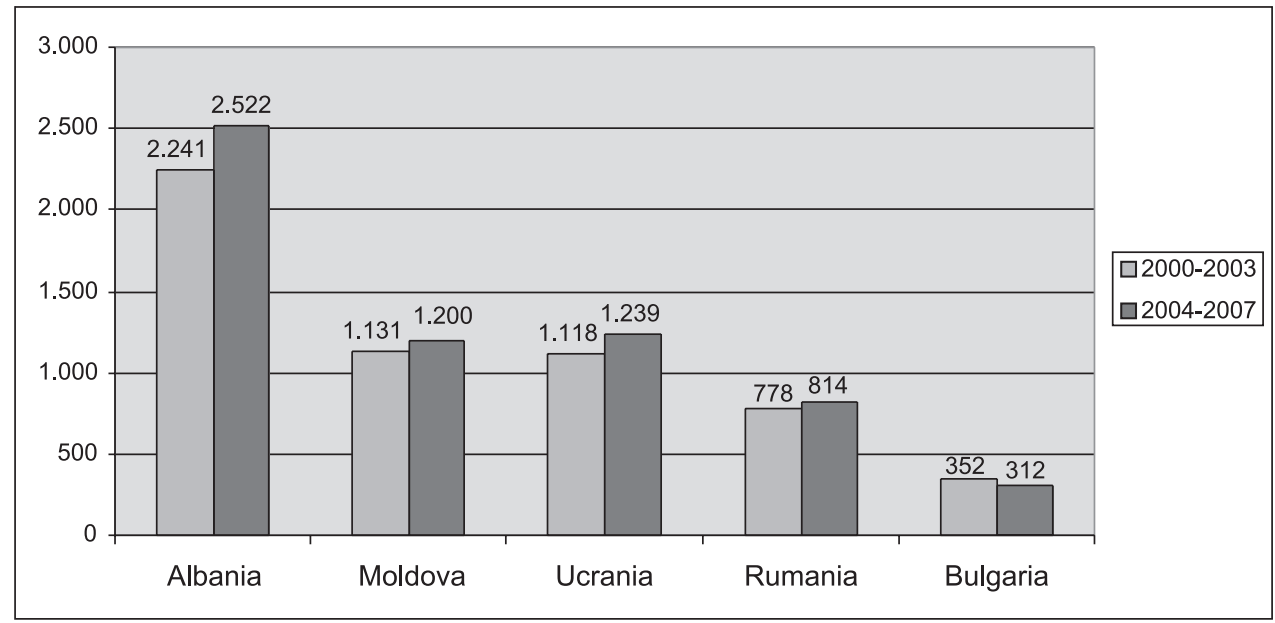

GráfiCo 1. Las víctimas asistidas del tráfico de personas en los países de la Europa Oriental 20002007.

Fuente: IOM, 2008.

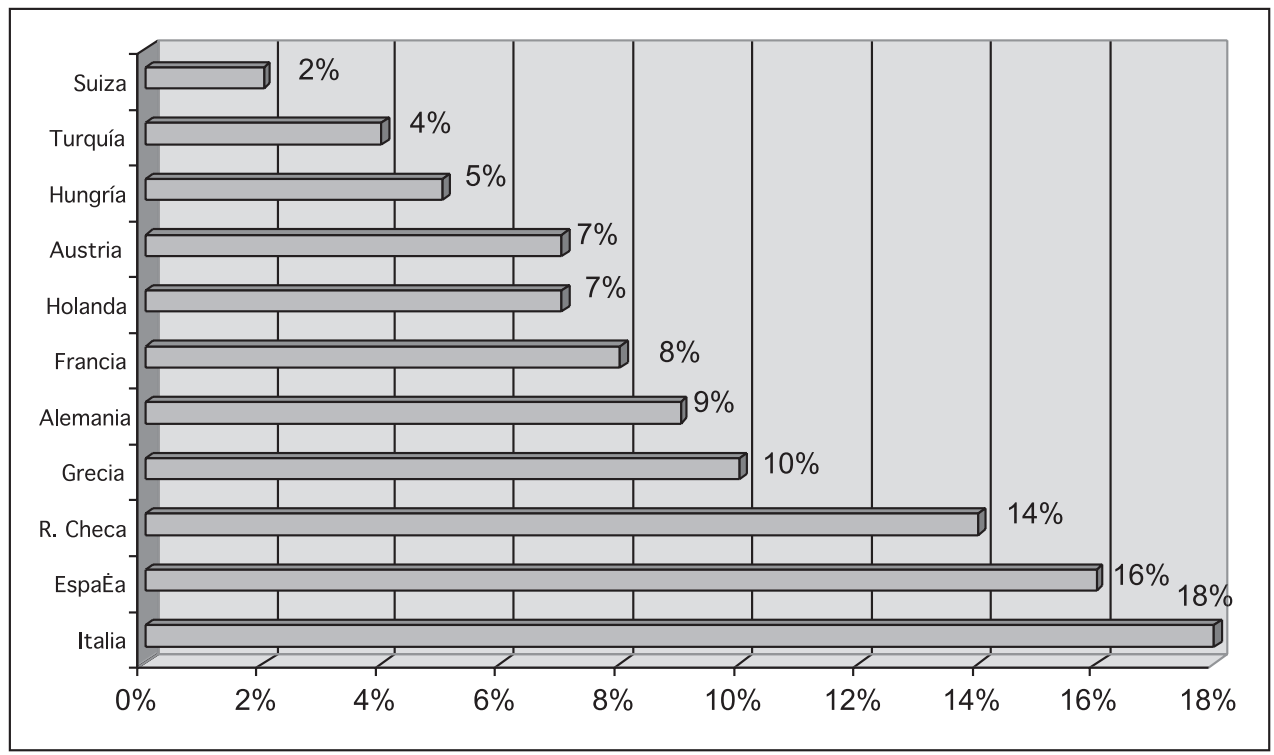

Gráfico 2. Mujeres de la Europa del Este, traficadas según el país de destino (UE) Fuente: IOM, 2007. 
En toda la región balcánica los puntos de control fronterizo son porosos, mal equipados, y los funcionarios son fácilmente corruptibles. En Europa se han creado ocho rutas que cruzan Rumanía y se dirigen hacia los países más desarrollados de la UE pasando por países de la antigua Yugoslavia. (Mapa 1)

A medida que Rumanía se aproximó a las estructuras euroatlánticas apareció la necesidad de confrontarse con presiones para solucionar el grave problema del tráfico. Se pensaba que la integración de Rumanía en la UE, podría constituir parte de la solución del problema a largo plazo, dado que se trataba de un tema económico. Pero no fue así.

Entre Rumanía y España existe una ruta directa que se realiza por la vía aérea y terrestre. Lo más a menudo se observa una tendencia de desplazamiento del fenómeno de la prostitución desde la esfera interna en la de la esfera de la criminalidad transfronteriza. Es una actividad que se profesionaliza cada vez más, al mismo tiempo que aumenta el nivel de organización de las redes de proxenetas. Los mercados se escogen según el grado de desarrollo y el nivel de vida del país de destino, pero también en función de la legislación y de las acciones concretas tomadas por los factores de decisión del país en cuestión. Asimismo, en el plano interno, prolifera la organización de la prostitución en redes dirigidas por los proxenetas. Además, las redes de prostitución se organizan bajo la apariencia de la ley.

\section{Inmigración rumana en la Comunidad de Madrid. Perfil de las víctimas}

En Rumanía, como en la mayoría de los países del Este europeo, la transición hacia una sociedad democrática, se mostró como un proceso largo y doloroso.

Uno de sus mayores efectos fue la disminución de los indicadores de la calidad de vida de la población. El desempleo aumentó y las estadísticas demostraron que durante la transición hacia la economía del mercado fueron las mujeres las primeras que perdieron su trabajo (Marcu, 2005). Con el telón de fondo de la pobreza, la falta de perspectiva, la violencia familiar, la pertenencia a familias desmembradas, muchas jóvenes llegaron en la situación de entrar en el circuito la migración irregular hacia países occidentales y en la industria del tráfico.

Después de la apertura de la frontera Schengen para Rumanía, en enero de 2002, y sobre todo, después de su ingreso en la UE, la inmigración irregular procedente de ese país aumentó, dado que los ciudadanos rumanos empezaron a circular libremente por el espacio comunitario.

Las cuotas más elevadas de rumanos en España se registraban en el año 2008, después de un año del ingreso del país en la Unión Europea. Solamente en la Comunidad de Madrid, vivían en junio de 2008, 195.676 rumanos, del total de 735.642 inmigrantes registrados en el padrón nacional (INE, 2008). A todos estos efectivos, es conveniente señalar a las personas que no están registradas en el padrón, que practican la migración circulatoria laboral, pero también a las personas que se dedican a la delincuencia. Es ésta, la cara ensombrecida de la inmigración rumana en España. El tráfico de mujeres, se incluye pues, en el amplio registro de las formas de delincuencia practicadas por los ciudadanos rumanos.

En los últimos años, se multiplicaron los grupos organizados de delincuentes rumanos en España, con predilección en la Comunidad de Madrid, donde suele comenzar el drama de los más débiles. Decenas de bandas rumanas dominan el negocio de la explotación sexual. Empezaron controlando la mendicidad y acabaron especializándose en el proxenetismo. Los datos son relevantes: entre 2000 y 2002, la Policía había desmantelado 660 redes de inmigración y explotación sexual y detenido a 1.843 responsables en toda España. Entre 2002 y 2007, en la CAM se desarticularon más de 100 bandas, detenidas 


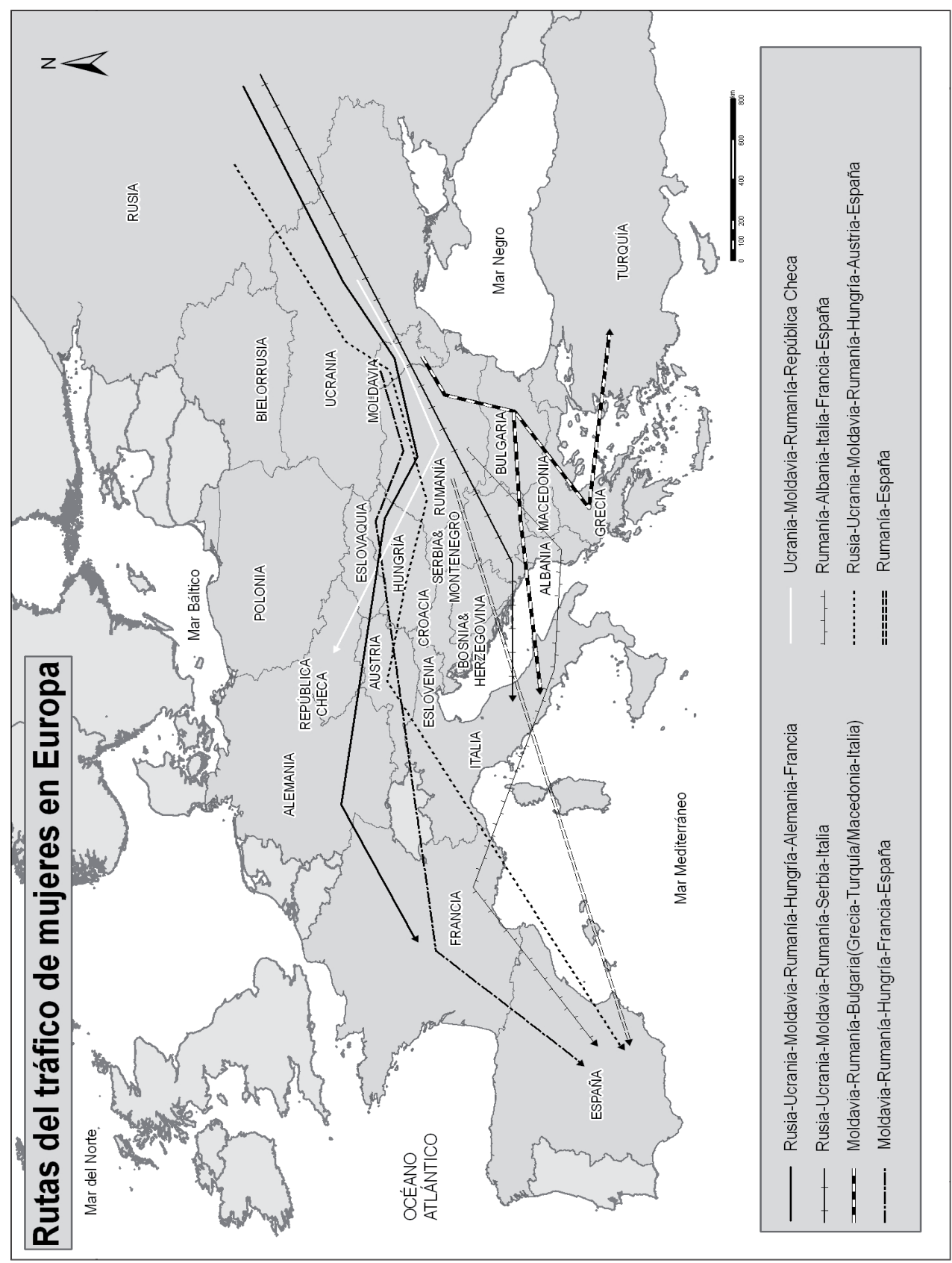


más de 2500 personas e identificadas cientos de mujeres traficadas ${ }^{9}$. La nacionalidad predominante de todas estas organizaciones es la rumana (más del 40\%), seguida de bandas nigerianas, lituanas y albano-kosovares. Los grupos de proxenetas rumanos se han consolidado en un negocio ilícito que mueve 2.400 millones de euros al año en Madrid, con cerca de 100 prostíbulos y unas 500 casas de citas, saunas y masajes dispersas por la región. Unas 30.000 mujeres traficadas y más de 1.000 proxenetas trabajan en este ambiente $^{10}$. Los delincuentes rumanos consiguieron establecerse con una cierta facilidad en España, por dos factores. En primer lugar, por la facilidad de entrada, al no necesitar visado. Los movimientos son sencillos, y existe una ruta directa Rumanía-España que se realiza en autobús. En segundo lugar, en España existe un escaso riesgo que les suponen los delitos ya que la actual legislación sobre la prostitución no lleva directamente a la prisión. Se trata de una organización muy fuerte, con proxenetas violentos sólo con sus compatriotas, multirreincidentes y nómadas, (cambian de lugar de residencia con frecuencia), (Serrano, 2004).

Las causas que conllevan al tráfico de mujeres desde el Este europeo, en este caso desde Rumanía, tienen la raíz en la crisis del proceso de transición hacia la economía de mercado. Señalamos el bajo nivel de vida de las víctimas. La mayor parte pertenece a familias en las cuales uno de los padres, o incluso ambos, están desempleados y se confrontan con grandes dificultades materiales. Algunas son mujeres que tienen una situación familiar difícil, jefas del hogar abandonadas por sus maridos, con hijos a cargo. La mayor parte proceden

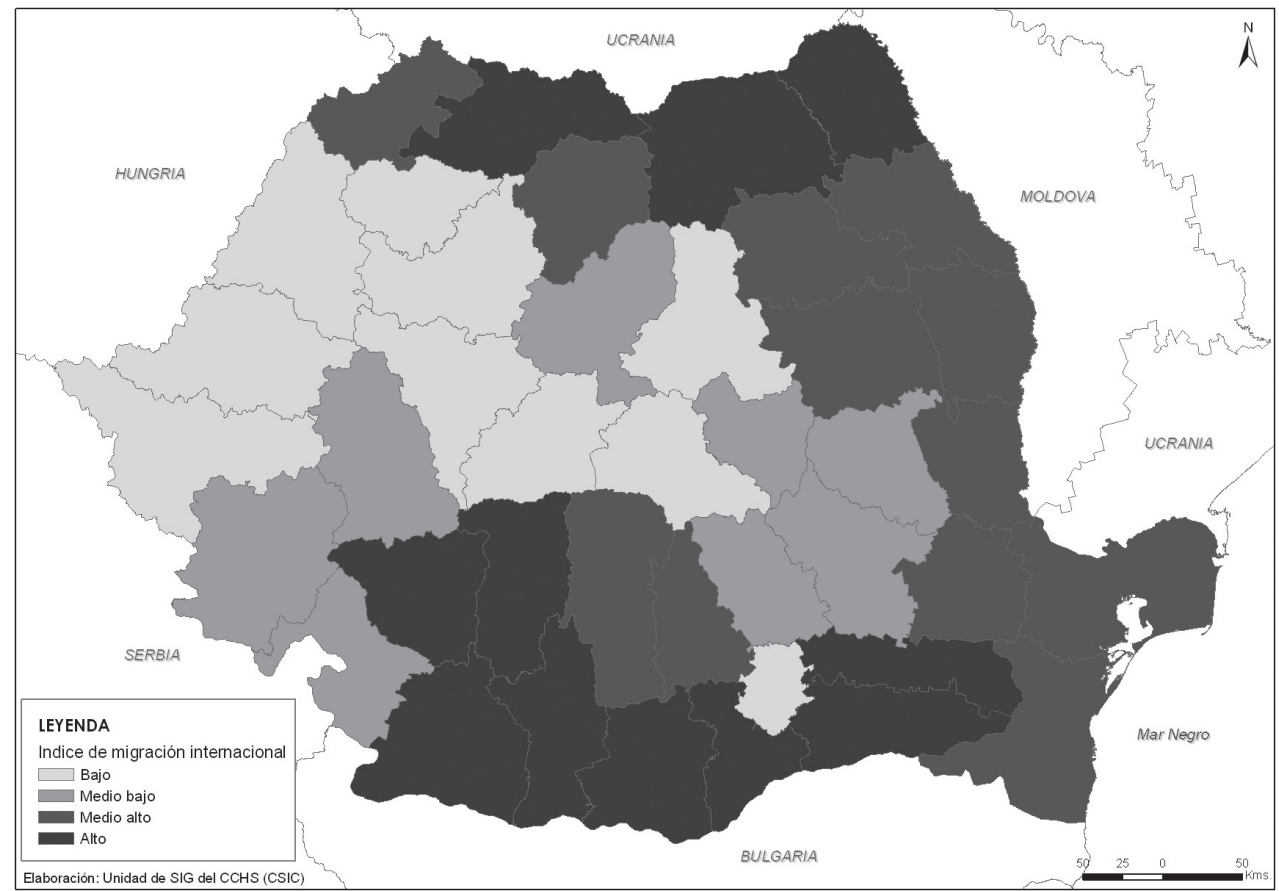

Fuentes: Datos ofrecidos por el INE, Oficio de Fuerza Laboral y de Migraciones de Rumanía, 2008.

9 Ministerio del Interior. Dirección General de Policía

10 Comunidad de Madrid, 2007. 
de Valaquia (en el Sur del país) y Moldavia (en el Este) las regiones más deprimidas de Rumanía donde se registra la mayor tasa de emigración internacional (Mapa).

Dado que a lo largo de la transición rumana hubo pocas perspectivas laborales, las mujeres buscaron métodos de ganancias por cualquier vía que les ayudara a satisfacer las necesidades básicas. La variación de la pobreza es responsable de la migración ilegal y del tráfico de personas, siendo más vulnerables, las personas sin recursos.

«No teníamos nada, mi padre había muerto en la mina antes de la Revolución. No estudiamos ninguno... Un día, mi mejor amiga me propuso ir a Serbia a trabajar. Desde allí, me llevaron a Albania, luego, llegué a Italia y ahora estoy a punto de regresar a casa desde España».

(D, 22 años, Braila)

La falta de puestos de trabajo y su poca cualificación hizo que las mujeres cayeran en las redes de los traficantes. Se tiene que evidenciar en el caso de las economías en transición, el bajo nivel de los salarios, que no cubren el mínimo de las necesidades.

«Me quedé sin empleo, y no podía sacar a mi hijo adelante. Mi marido y yo, decidimos que me fuera a trabajar de camarera a España. Me engañaron, y lo peor de todo es que fue mi cuñada la que me engañó. Tuve que aceptarlo todo para ayudar a los míos.»

(R, 25 años, Suceava)

Destaca, asimismo, el escaso nivel de formación, (gráfico 3) puesto que la mayor parte de las jóvenes traficadas no acabaron el ciclo obligatorio de estudios, y tienen una media de reducida. (20-22 años). Al no tener una cualificación adecuada, tampoco poseen experiencia en el mercado de trabajo y son más vulnerables.

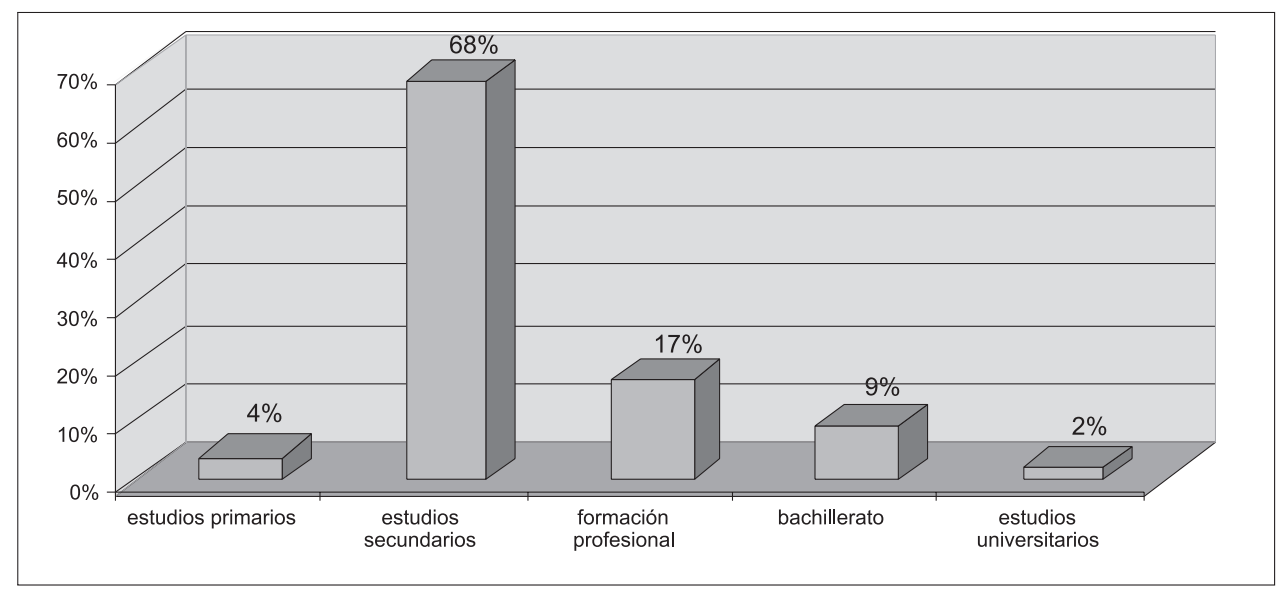

GRÁFICo 3. Distribución de las víctimas de tráfico de mujeres rumanas en España por niveles de educación $(\%)$

Fuente: Rapid Assessment Survey on Human Trafficking from Romania. For purposes of Labor and Sexual Exploitation, Informe elaborado por el Instituto de investigaciones en el ámbito laboral y de la protección social, 2007, Bucarest. 
El nivel de educación recibido en el ámbito familiar y social constituye el factor de responsabilidad como actitud frente a las normas sociales, como capacidad de relación lúcida, realista con las circunstancias que aparecen en la vida personal, en la cual se incluyen de manera decisiva las alternativas ocupacionales. La falta de educación convierte a las mujeres en víctimas que no saben ni pueden orientarse en los países de destino hacia otros tipos de trabajos.

Por ello, el ámbito familiar se convierte en otra causa del tráfico. Las mujeres proceden generalmente, de familias en las que el alcoholismo, la falta de afecto, los conflictos y los antecedentes penales son una constante de la que se aprovechan los traficantes, que muestran interés de naturaleza afectiva frente a las victimas en el momento de su captación, ya que muchas intentan escapar de un ámbito familiar dominado por la violencia.

«Mis padres se divorciaron cuando era niña, y luego me quedé con la abuela. No estudié, y empecé a trabajar en un bar a los 15 años. Me cogieron a los 16 años y luego me trajeron aquí.»

(B, 17 años, Calarasi)

Otra causa es la percepción del capitalismo occidental como «modelo de éxito». Del análisis de las investigaciones emprendidas en el ámbito del tráfico de mujeres resultó que la principal causa de los jóvenes que emigran lo representa la percepción de los individuos acerca de sus posibilidades de autorrealización. (Sandu, op.cit)

"Un amigo me propuso ir a trabajar fuera porque se ganaba mejor. Quería vivir por mi misma sin necesidad de pedir dinero a mis padres. Me impresionó la historia de dos vecinas mías que decían que ganaban muy bien en España y, aunque mi madre no estuvo de acuerdo con la idea, no la escuché. Pensaba que el Occidente era mejor, pero no es así».

(C, 23 años, Bucarest)

En un ámbito en el cual las oportunidades ofrecidas a la generación joven son reducidas, aparece la decisión de la mayoría a considerar que podrían realizar sus sueños en el Occidente. A muchas jóvenes se les expusieron casos sobre la emigración de éxito, lo que aumentó su grado de vulnerabilidad.

Además, hay una serie de factores endógenos que se constituyen al nivel individual como predisposición para una tal orientación ocupacional: las deficiencias de carácter estructural de la personalidad de las mujeres implicadas en el tráfico: labilidad psíquica, alienación, orientación anti-social; las consecuencias del debut de la vida sexual en el periodo de adolescencia y las posibles agresiones sexuales anteriores; el deseo de independencia; vivir en un ámbito institucional hasta la mayoría de edad, las experiencias que suelen contar los medios de comunicación, la influencia de los círculos de amigos y conocidos, la legislación que no prevé sanciones para los traficantes y sobre todo, no ofrece soluciones para las víctimas, constituyen otras causas para que el mercado prospere.

\section{La logística del proceso. redes y etapas del tráfico y de la trata de mujeres}

En el proceso de tráfico y trata de mujeres hay tres etapas (esquema 1): reclutamiento, transporte y explotación. 


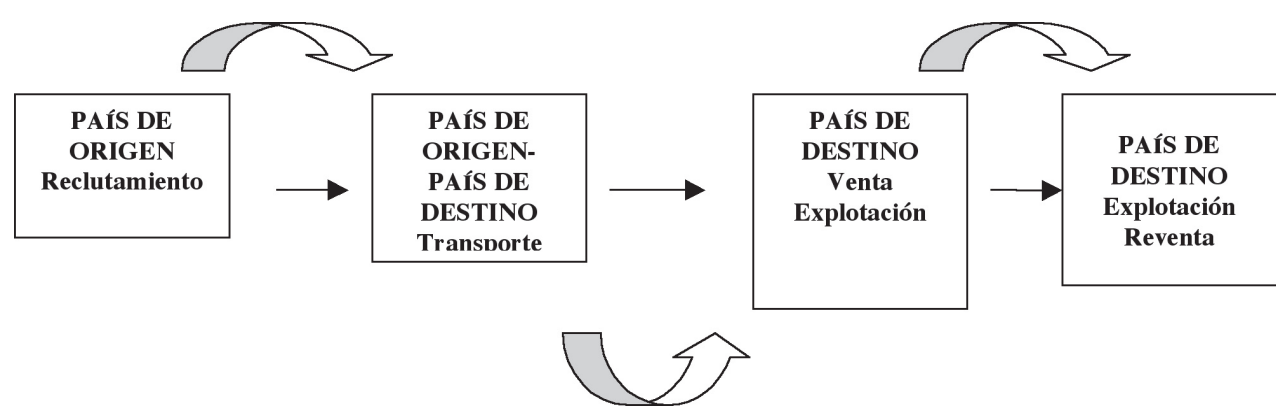

ESQuema 1. Las etapas del tráfico y trata de mujeres

Fuente: Elaboración propia según información del Ministerio del Interior, Rumanía, 2008.

1. El reclutamiento se lleva a cabo utilizando varios métodos. El más empleado consiste en publicar anuncios en los periódicos, en los que se prometen trabajos bien remunerados en el occidente, o matrimonios con ciudadanos occidentales. Se trata de falsas promesas y ofertas de trabajo en España (camareras, cocineras, bailarinas, baby-sitter, limpiadoras) hechas directamente a las víctimas mediante conocidos, parientes, o personas del entorno próximo. Se recurre a anuncios en periódicos de tipo: «Se necesitan jóvenes bailarinas para España. Salida inmediata». ${ }^{11}$

El proceso de reclutamiento lo organizan los grupos organizados que colaboraron incluso antes traficando con drogas o con dinero negro. Pero también existen redes más reducidas de tráfico, incluso traficantes en solitario. Las redes rumanas de tráfico se organizan según un modelo clásico e incluyen: los reclutadores - personas dedicadas a captar a las víctimas prometiéndoles, por lo general, un trabajo en el Occidente; los transportistas, que realizan el transporte de las víctimas hasta la frontera; las guías, encargadas de acompañar a las víctimas en el paso de las fronteras; los organizadores de grupo, los que supervisan todo el proceso de tráfico (el reclutamiento, el transporte y la venta de la víctima). En el caso del tráfico de mujeres rumanas hacia la Comunidad de Madrid, existen dos categorías de proxenetas reclutadores:

a) Los intermediarios - realizan el contacto víctima-cliente, de manera ocasional. Los encontramos, sobre todo, en el territorio rumano, pero también aprovechan a los conocidos que viven en el extranjero, en este caso en la Comunidad de Madrid.

b) Los profesionales - se dedican al negocio del tráfico y obtienen grandes beneficios materiales. En esta categoría se incluyen antiguas víctimas que aprovechan su experiencia y sus relaciones. Los traficantes profesionales se dirigen cada vez más hacia el tráfico internacional con destino Madrid, dado que está bien remunerado, a pesar de ser más arriesgado. Recurren a diferentes métodos de reclutamiento de las víctimas que van desde varios tipos de abordajes a falsas promesas de puestos de trabajo en la capital española.

«Me dijeron que trabajaría de bailarina. Hice ballet clásico durante 10 años, así que me apunté. Vivía mal, porque no tenía trabajo y no pude tampoco seguir mis estudios. Yo pensaba que tenía que bailar en el teatro, de bailarina clásica. Llamé y me dijeron que salíamos en el autobús en cuatro días...»

(M, 19 años, Galati)

11 România Libera. www.romaniallibera.ro. 11 de noviembre de 2007. 
Los traficantes proxenetas practican esta actividad para aumentar sus ganancias. Hay que tener en cuenta que no son personas que se encuentren al límite de subsistencia, ni mucho menos.

El mayor proxeneta rumano que actúa en España y en la Comunidad de Madrid, se encuentra todavía en libertad. I C., «El Padrino», «El Papa» o «La cabeza de cerdo», fue condenado a 15 años de cárcel por homicidio, pero quedó en libertad condicional en 1999. Inició a en 2001, una red en España que tenía como modelo de acción las reglas y castigos utilizados por la Camorra italiana ${ }^{12}$.

2. La segunda etapa del tráfico la constituye el transporte, que puede ser distinto, según la ruta a seguir. Si bien, como señalamos más arriba, en Europa hay ocho grandes rutas de tráfico, entre Rumanía y España hay una ruta permanente que funciona desde principios del año 2002, cuando entraron en vigor las líneas directas de autobús con trayecto entre varias ciudades de Rumanía y de España.

El viaje se organiza junto a una guía y en el destino, los traficantes les confiscan los pasaportes a las víctimas, obligándoles a prostituirse.

Las situaciones límite a las que están sometidas las rumanas son, además de ser desprovistas de los documentos de viaje, el aprovechamiento de la falta de conocimiento del idioma en el país de destino, el empleo de la violencia, las diversas formas de amenazas, represalias contra sus familias, el chantaje, la amenaza con la muerte, la falta de comida, la obligación a consumir drogas, la privación de la libertad. Algunas mujeres consiguen escapar y reciben protección policial; pero algunas de ellas pueden llegar a ser capturadas nuevamente por los traficantes, son perseguidas o amenazadas, incluso en los centros de protección.

En el caso aquí tratado, hemos detectado mediante estudio exploratorio, tres categorías de reclutadores y transportistas: en primer lugar, hombres, con edades comprendidas entre 20 y 30 años (un 70\%), en el segundo, mujeres (con edades comprendidas entre 18 y 35 años) y por último, familias.

$\mathrm{Al}$ desarrollarse el proceso de tráfico directamente, la venta de las víctimas se realiza en ciudades rumanas o en Madrid. Antes del ingreso del país en la UE la venta se realizaba, frecuentemente, en los países de tránsito (Serbia, Albania, Kosovo, Turquía). El aspecto físico y la edad son las características que fijan el precio de venta (por regla general, entre 1.000 y 4.000-5.000 euros).

«No me di cuenta, pero creo que pasamos por Albania y luego por Italia. Fue allí donde me quedé mucho tiempo. Luego llegué a España. El pasaporte me lo habían quitado desde que salimos de Rumanía».

(V. 19 años, Teleorman)

El viaje se suele realizar con la ayuda de las guías, y puede ser: legal, bajo el pretexto de un viaje, en el caso en el cual las víctimas poseen pasaportes, o ilegal, en el caso de las menores, o personas sin pasaportes. Se comprobó que, en su mayor parte, durante el transporte, a las víctimas se les trata de modo civilizado, se les ofrecen alojamiento y comida, y pueden tener contacto con las familias.

«En el autobús me trataron bien, o sea... tampoco me hablaron mucho, pero comí y pude llamar a mi familia. Vamos, normal...»

(M., 19 años, Galati)

12 Adevărul, 18 de enero de 2007. 
Antes de 2007 sus presuntos contratantes les facilitaban a las víctimas la documentación necesaria para traspasar la frontera — documentos que solían costar alrededor de 400-500 euros - y organizaban el viaje. Dado que desde 2002 no se precisaron visados, se prepararon auténticos viajes regulares a España a través de diversas compañías de autobuses. En Austria, en la frontera Schengen, entregaban los pasaportes y justificaban con el dinero que llevaban, que eran turistas. Otras veces se dirigían a Italia y desde ahí llegaban a España. Después de 2007, las cosas fueron más fáciles aún más para los reclutadores y los transportistas.

Tras dos o tres días de viaje, se llega a Madrid. El intercambiador de la estación de Méndez Álvaro en la capital española se convirtió en uno de los puntos álgidos, donde arriban a diario decenas de autobuses con mujeres que desconocen su verdadero destino. El desenlace, una vez en Madrid, suele ser el mismo: a las víctimas se les quitan las pertenencias: dinero, pasaportes, cualquier otra documentación, y se las recluyen en pisos francos desde donde se las distribuyen por clubes, prostíbulos o en las calles, para que comiencen a rendir. Surge, casi siempre, el fantasma de la deuda: no podrán liberarse hasta que paguen entre 1.500 y 40.000 euros a sus jefes. Y para ello se les exige que ganen una media de 300 euros al día, de los que la mafia se queda al menos el 50\%. Con ello, invierten en negocios inmobiliarios y en asegurarse una sólida red de abogados con los que cubrirse legalmente.

«Cada día teníamos que salir a trabajar, mi madre y yo. Si no, nos amenazaban con la muerte. Nuestra deuda alcanzó 7.000 euros y nos costó bastante tiempo para saldarla...»

(V. 23, Timisoara)

La red de proxenetas acciona sin piedad, recurre a violencias físicas para convencer a las víctimas, vender su cuerpo y producir ganancias. El método empleado con más frecuencia y dureza es la paliza que se les aplica a las víctimas más antiguas, delante de las nuevas. De esta manera, los traficantes demuestran que cualquier insumisión se castiga.

«Entré en casa, tenía hambre y me sentía mareada. Vi una chica semidesnuda en un rincón, llorando. Un hombre la golpeaba sin piedad. Me dijeron que a mi también me esperaba lo mismo si no hacía lo que se me decía. Me dieron una falda muy corta y una camiseta. Mi vida acabó en aquél momento...»

(D. 22 años, Braila)

3. La explotación de las víctimas constituye el punto álgido de las etapas del tráfico. Es allí donde la víctima vive su propio drama, la realidad a la que se tiene que someter. El secuestro se realiza en lugares cerrados, en los que faltan las posibilidades de comunicación (documentos de identidad, teléfonos móviles). El tratamiento aplicado a las víctimas es el aislamiento, la violación cometida por uno o varios maltratadores, amenazas, e, incluso, crímenes.

«Me negué a salir a la calle. Me pegaron... violaron. Estaba embarazada... aborté. Me dolió mucho, pero ahora pienso que fue para mejor si puedo decir esto, porque si no, hubieran vendido al pequeño...Lo único que quiero es salir corriendo de aquí, y curarme en mi país».

(N, 21 años, Craiova) 
Los espeluznantes testimonios de las víctimas ponen de manifiesto el terror al cual se les sometió. Generalmente, las chicas están obligadas a prostituirse en la Casa de Campo, que en el argot de los traficantes rumanos se llama «la fábrica». Pero también se las coloca en la conocida calle Montera, situada en el centro de la ciudad. Los barrios del centro, Usera, Villaverde y Carabanchel, así como la periferia de la capital y provincias limítrofes son los puntos donde más se mueven estas redes que procuran no fijar lugares donde establecerse para poder burlar a las fuerzas de seguridad. Fuera de la región, algunos polígonos de Fuenlabrada, como el de la Cantueña, y las afueras de Alcalá de Henares y Torrejón de Ardoz concentran el mayor número de víctimas rumanas de la prostitución. Nunca se les ve en el centro de estas localidades, sino en las afueras. Las rotondas y las vías de servicio son su lugar de trabajo fuera de la capital. La mayoría ejerce de día (al contrario que en la capital), a excepción de la Colonia Marconi.

Los sitios donde se colocan las chicas se llaman «puestos», mientras que ellas llevan el nombre de «bagajes» o «paquetes». Cada noche, alrededor de 300 chicas salen a «producir» en la «fábrica». Su actividad está controlada en todo momento por los proxenetas que no tienen ningún impedimento en eliminar mediante cualquier método a las que no se someten a las reglas impuestas.

«Todas las chicas nos íbamos de casa alrededor de las nueve de la noche y nos quedábamos en la Casa de Campo hasta las dos o incluso las cuatro de la mañana. Permanentemente, nos controlaban varios chicos rumanos que circulaban en coches con matrículas españolas y que no nos permitían hablar entre nosotras. Nos amenazaban continuamente, y nos pegaban sin ningún motivo».

(V, 20 años, Giurgiu)

El tráfico se incluye en el entramado económico de la región madrileña. Hablamos, pues, de la industria del sexo donde las víctimas están obligadas a prostituirse. Junto a la oferta, hay pues, demanda, ya que en la CAM existe una numerosa y variada clientela (gráfico 5)

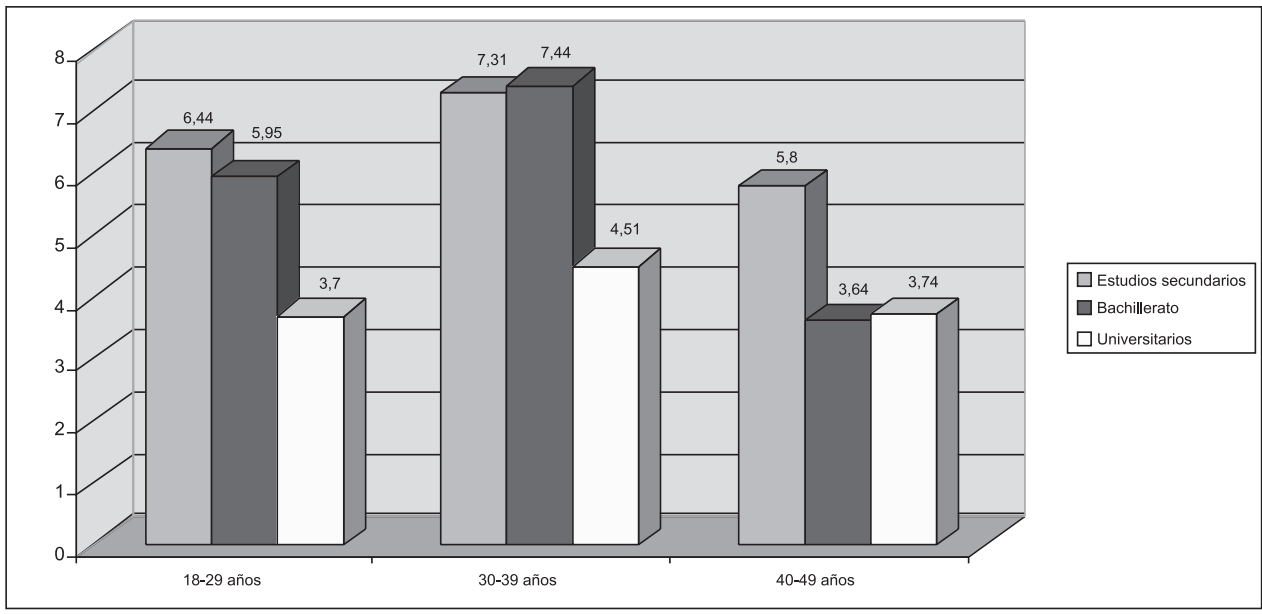

GráfICo 4 El perfil del cliente en la CAM.

Fuente: Datos de la Ponencia sobre la prostitución en España, de 2007. 
que atrae y responde a los agentes mediadores, en este caso, a los proxenetas. Por tanto, proxenetas y clientes movilizan, canalizan y facilitan el funcionamiento del negocio de la prostitución de las víctimas del tráfico de mujeres.

La cabeza de la red existente en Madrid tiene reglas estrictas para sus víctimas, que deben aceptar solamente clientes españoles, rechazando a rumanos, búlgaros, albaneses o marroquíes. Se les obliga a quedarse cada una en un puesto situado a aproximadamente cinco metros la una de la otra. No pueden hablar entre sí, y las ganancias se tienen que entregar integralmente por la mañana al proxeneta designado en cada área. Un importante porcentaje se le entrega al jefe de la red.

«Cada noche tenía miedo, porque no sabía lo que me esperaba, pero temía, todavía temo continuamente por mi hijo de Rumanía, por toda la familia. Me dijeron que si no obedecía cada noche, todos morirían. Así que dos años enteros hice lo mismo, deseando morir en cada momento.

(R. 25 años, Suceava).

Las chicas tienen teléfonos móviles, la mayor parte sin crédito, a los que llaman los proxenetas que les controlan y les explican cómo atraer a los clientes.

«Obtenía por noche como media unos 500-600 euro, de los que la mitad se los daba a Elena la ayudante de Nicu. Me quedaba prácticamente la cuarta parte del dinero. El dinero se registraba en un cuaderno donde se apuntaban todas las deudas y todo el dinero obtenido por cada chica. Cuando se llegaba a 2000 o 3000 euro, el dinero se entregaba a Nicu o a otros chicos. En mi primer día, me acompañó Elena a una tienda de donde me compré varias cosas en valor de 300 euros. El dinero entró en la cuenta de mi deuda. De hecho, fue entonces cuando otra chica me quitó el pasaporte. Elena me dio unos papeles para demostrar donde estaba y

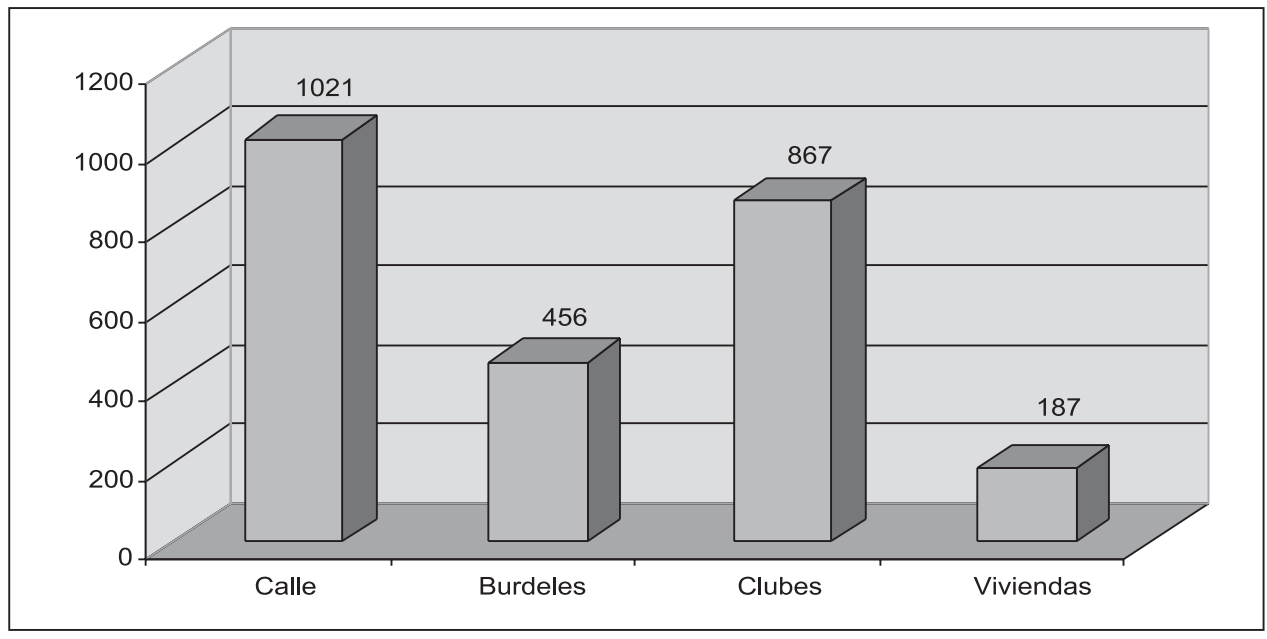

Gráfico 5. Víctimas asistidas del tráfico de mujeres rumanas en la Comunidad de Madrid (2007) según el lugar de explotación.

Fuente: Comunidad de Madrid, 2007. 
la falta del pasaporte. Fue lo que me dijo. Estos documentos me costaron otros 300 euros. Finalmente, mi deuda aumentó a 2000 euro».

(C, 23 años, Bucarest)

Los proxenetas se saben impunes, además, porque tienen aleccionadas a las víctimas. Los rumanos, según la policía, son los proxenetas que con más dureza se emplean con las mujeres. Controlan hasta las salidas que éstas puedan hacer con clientes y no les dejan repetir a menudo con el mismo por si acaban consiguiendo que éste les ofrezca su ayuda.

Según el tipo de explotación, la mayor parte de las víctimas rumanas del tráfico lo sufren en la calle. (Gráfico 5).

Aunque en el caso rumano se da menos, detectamos también la etapa de reventa. Las víctimas entran en una fase de falsas deudas, puesto que los compradores pretenden que deben recuperar el dinero de su trabajo. En la mayoría de los casos sigue una reventa hacia otro patrón que, a su vez, desea recuperar la cantidad pagada. La denuncia se produce como consecuencia de la huída que la víctima realiza, en su mayor parte, con la ayuda de la policía española que efectúa redadas.

«Llamé por teléfono en un descuido de la chica que me controlaba. Estaba medio muerta porque me habían pegado y violado. Luego ellos se quedaron dormidos y llamé a la Policía desde un teléfono suyo, creo que era pinchado, no sé. En la misma noche, antes de salir de casa, se presentó la policía al piso y rompió la puerta. Nos cogió a todos y nos llevaron a la Comisaría. Ahora, estoy esperando el pasaporte para regresar a mi país.»

(V, 20 años, Giurgiu)

A cambio de las denuncias, según el artículo 59 de la Ley de Extranjería tienen la posibilidad de que la Administración las financie el retorno a su país o bien las conceda el permiso de residencia, una tarjeta de trabajo y aplicación de Ley de Protección a Testigos. «La condición es que la víctima ratifique ante el juez lo que antes había denunciado y esta denuncia sea veraz. Y lo cierto es que esos testimonios son fundamentales para llegar a los núcleos de estas mafias que tanto están proliferando ${ }^{13}$. La repatriación se realiza con el apoyo de la, la Policía, la Embajada y los Consulados de Rumanía en España, que se ocupan con los trámites de repatriación. A las víctimas se les ofrece un pasaporte consular y documentos de viaje. La recepción en Rumanía se realiza por el equipo de asistencia de la Organización Internacional de Migraciones, que las integran en los programas de asistencia para las víctimas del tráfico de mujeres y de prevención del tráfico en Rumanía.

En los últimos años, ha habido incluso implicación policial en el tráfico de mujeres rumanas en la Comunidad de Madrid. En marzo de 2008 se investigó una trama de tráfico y prostitución de mujeres de origen rumano, a raíz de las denuncias de varias mujeres que ofrecían sus servicios en un polígono de Vicálvaro. La Policía Judicial reveló que varios policías locales de Coslada extorsionaban a estas víctimas. Al mismo tiempo, varios empresarios denunciaron el acoso que sufrían por parte del jefe del Cuerpo de Policía de la localidad $^{14}$.

13 Policía Nacional, Ministerio del Interior, 2008.

14 Dirección General de Policía, Informe, Madrid, julio de 2008. 


\section{Conclusiones: asistencia de las víctimas en origen y destino}

El análisis realizó una aproximación a la dramática situación de las mujeres rumanas, víctimas de las mafias que las trafican y las convierten en esclavas sexuales. El enfoque del análisis se centró en el fracaso de la migración circulatoria rumana, vista como estrategia de innovación social. En el mercado del tráfico, la fuerza de trabajo se emplea de manera abusiva, mediante engaños, mientras que la relación entre el capital humano y laboral está interrumpida por las redes e intereses financieros ocultos.

Las acciones cometidas por los reclutadores, guías, secuestradores, traficantes se consideran como graves infracciones, castigadas en Rumanía ${ }^{15}$, país que continúa registrando progresos en lo que se refiere a la lucha contra el tráfico de mujeres pero todavía existen dificultades en identificar a las víctimas de estas actividades y en la creación de un sistema funcional de asistencia. Según el Informe del 2007 del Departamento de Estado, el Gobierno Rumano no cumple los estándares mínimos con vista en la eliminación del tráfico de mujeres. Evitar el fracaso al nivel colectivo necesita la realización de políticas institucionales que tengan como objetivo la libre circulación de la información, el aumento del stock del capital humano, la transformación de las mentalidades o la absorción de prácticas democráticas.

Por otra parte, la CAM está en un continuo debate: lanzó en 2005 su campaña contra el consumidor de sexo: «Porque tú pagas, existe la prostitución». Y en 2004 puso en marcha el Plan contra la Explotación Sexual, que, a través de promesas en medidas sociales, policiales y administrativas quiso tranquilizar a los ciudadanos. Las Asociaciones de lucha contra el tráfico coincidieron en que el Plan contra la Explotación Sexual haya sido un fracaso. Desde la Concejalía de Servicios Sociales, se señala como balance, que en los últimos tres años sus servicios han atendido miles de víctimas en todo Madrid y que 50 participan en cursos de formación para abandonar la prostitución. Además, ha aumentado el número de policías que piden la documentación a las víctimas. El plan incluye una unidad móvil que contacta con las víctimas en diferentes puntos de la ciudad para ofrecerles alternativas. Un centro de día donde se realizan planes individuales para las víctimas y talleres de formación con cursos de peluquería o geriatría. La mujer que decide denunciar, no será expulsada, pero si decide regresar a su país recibe gratis el billete de avión. La asociación Hetaira aboga por regular la prostitución, ya que, en su opinión por esta vía se solucionarán los problemas de tráfico y trata. En las antípodas ideológicas — defiende la abolición de la prostitución - está la Asociación para la Prevención, Reinserción y Atención de la Mujer Prostituida (APRAMP). Pero coincide con Hetaira en calificar el plan del Ayuntamiento de «fracaso». El debate sobre la regularización de la prostitución sigue, pues, abierto en España, en la Comunidad de Madrid, y las medidas tomadas afectarán también a las mujeres rumanas traficadas en la región.

\section{Bibliografía}

AGUSTÍN, L. (2006): The disappearing of a migration category: Migrants who sell sex, Journal of Ethnic and Migration Studies, $\mathrm{n}^{\circ}$ 32, (1) pp. 29-47.

BARAJONA, G. M. (coord.) (2001): Tipología de la Prostitución Femenina en la Comunidad de Madrid. Madrid: Dirección General de la Mujer.

15 La Ley sobre la prevención y la lucha contra el tráfico de personas, publicada el el Monitor Oficial $n^{\circ}$ 783/11 de diciembre de 2001, y el Código Penal de Urgencia n 112/2001). 
BEDOYA, M. H. (2000): Mujer extranjera: una doble exclusión, en Papers, nº 60, pp 30-45.

BORNELLI, E. y ULLOA, M. (2001): Tráfico e inmigración de mujeres en España: colombianas y ecuatorianas en los servicios domésticos y sexuales ACSUR.

BOSWELL, C. (2002): Addressing the Root Causes of Migratory and Refugee Movements: The Role of the European Union, Working Paper, 73. Evaluation and Policy Analysis Unit, UNHCR, Geneva.

BUSTAMANTE, J. (2002): Immigrants Vulnerability as Subjects of Human Rights, International Migration Review, no 36, Summer, pp. 333-354.

HOLGADO FERNÁNDEZ, I. (2001): Las nuevas retóricas de la inmigración femenina: la prostitución en las calles de Barcelona, en Scripta Nova, $n^{\circ} .94$ (100).

HUGHES, D. (2000): The Natasha trade: the transnational shadow market of trafficking in women, en Journal of International Affairs, $n^{\circ}$ 53, (2), pp. 625-651.

INSTITUTO NACIONAL DE ESTADÍSTICA (INE), (2008): www.ine.es.

JANDL, M. (2007): Irregular Migration, Human Smuggling, and the Eastern Enlargement of the European Union en International Migration Revue, $\mathrm{n}^{\circ}$ 41, (2) pp 291-315, (293).

JANDL, M. y KARSAKOVA, L. (2005): A Survey of Illegal Migration and Human Smuggling in Central and Eastern Europe en Migracijske I Etnicke Teme/Migration and Ethnic Studies, $\mathrm{n}^{\mathrm{o}}$ 21(1-2) pp. 35-54.

KYLE, D., y KOSLOWSKI, R. ed. (2001): Global Human Smuggling: Comparative Perspectives. Johns Hopkins University Press. Cambridge.

KELLY, E. (2005): You can find anything you want: research on human trafficking in Europe in the twenty-first century, en International Migration, $\mathrm{n}^{\circ}$. 43(1/2).

LACZKO, F. y GRAMEGNA, M.A. (2003): Developing Better Indicators of Human Trafficking, en The Brown Journal of world affairs. Vol. X, (1), pp. 179-194.

LACZKO, F. KLEKOWSKI VON KOPPENFELS, A. y BARTHEL, J. (2002): Trafficking in Women from Central and Eastern Europe: A Review of Statistical Data, en New Challenges for Migration Policy in Central and Eastern Europe, eds, F. Laczko, I. Stacher and A. Klekowski von Koppenfels, Asser Press, The Hague, forthcoming, 2002.

LAYARD, R. BLANCHARD, O. DORNBUSC y KRUGMAN, P. (1992): East-west migration: The Alternative. Mit Press. Cambridge.

L Z ROIU, S. (2000): Trafic de femei - o perspectivã sociologicã en „Sociologie româneasc », no 2 , pp. 55-79.

LEMAN, J. y JANSSENS, S. (2007): The various Safe -House Profiles in East-European Human Smuggling and Trafficking en Journal of Ethnic and Migration Studies, Volume 33, $\mathrm{n}^{\circ}$ 8, November, pp. 1377-1388.

LOESCHER, G. (2001): The UNHCR and world politics: A perilous path. UK, University Press. Oxford.

MARCU, S. (2005): Rumanía, territorio olvidado. Procesos de transición e integración: 1989-2005. Servicio de Publicaciones, Universidad de Valladolid, 298 páginas.

MAVRIS, L. (2002): Human Smugglers and Social Networks: Transit Migration through the States of FormerYugoslavia en New Issues in Refugee Research, Working paper (72) Geneva: Evaluation and Policy Analysis Unit, UNHCR.

MOROKVASIC-MULLER M. (1984): Birds of passage are also Women en International Migration Review, no. 68 (18) pp. 886-907.

NIEUWENHUYS, C. y PÉCOUD, A. (2007): Control Human Trafficking, Information Campaigns, and Strategies of Migration en American Behavioral Scientist; ${ }^{\circ} 50$ (12) pp. 1674-1695.

OIM (2006): IOM Counter Trafficking Strategy for the Balkans and Neighbouring Countries.

OIM (2007): Victims of Trafficking in the Balkans. A study of trafficking in women and children for sexual exploitation to, through and from the Balkan Region.

OIM (2003): Stability Pact for South Eastern Europe, ICMC. Viena, en First Annual Report on Victims of Trafficking in South Eastern Europe.

PYSHCHULINA, O. (2003): An evaluation of Ukrainian legislation to counter and criminalize human trafficking, en Demokratizatsiya, $\mathrm{n}^{\circ} .11$ (3) pp. 403-11. 
RECHEA-ALBEROLA, C. (2007): The co-operation of law enforcement agencies and NGOs in the prevention of and support for victims of trafficking in persons for the purpose of sexual exploitation en Report of Centro de Investigación en Criminología, UCLM. Available in http://www. uclm.es/Criminologia/pdf/14-2007.pdf.

SALT, J., y STEIN, J. (1997): Migration as a Business: The Case of Trafficking, en International Migration, $n^{\circ} .35(4)$ pp. 467-494.

SANDU, D. (2006): Exploring Europe through work migrations: 1990-2006, Living abroad on a temporary basis. The economic migration of Romanian: 1990-2006. Open Society Foundation, Bucuresti.

SERRANO, J.C. (2004): Los papas del crímen organizado en La Razón, 15.II., 50-51.

SMARTT, U. (2003): Human trafficking: simply a European problem? En European Journal of Crime, Criminal Law and Criminal Justice, $\mathrm{n}^{\circ}$ 11(2) pp. 164-177.

SKROBANEK, S. BOONPAKDI, N. y JANTHAKEERO, C. (1999): Tráfico de mujeres. Realidades humanas en el negocio internacional del sexo Madrid: Libros Aula Magna.

TYLDUM G., y BRUNOVSKIS, A. (2005): Current practices and challenges in empirical studies on trafficking: a discussion paper from a northern European perspective, en International Migration, $n^{\circ} .43(1 / 2)$.

UEHLING, G. (2004): Irregular and Illegal Migration through Ukraine, en International Migration, $n^{\circ}$ 42(3) pp. 77-109.

WALLACE, C. (2002): Opening and closing borders: migration and mobility in East- Central, en Europe Journal of Ethnic and Migration Studies, $n^{\circ} .28$, (4) pp. 603-625. 
